\title{
6
}

\section{/1/ PÓS-VOCÁLICO EM ALTO ALEGRE: FATORES SOCIAIS}

POSTVOCALIC /1/ IN ALTO ALEGRE: SOCIAL FACTORS

\author{
Robevaldo Correia dos Santos 1 \\ Universidade Federal da Bahia \\ Jacyra Andrade Mota ${ }^{2}$ \\ Universidade Federal da Bahia \\ Gredson dos Santos 3 \\ Universidade Federal da Bahia
}

\begin{abstract}
Resumo: Este estudo tem cunho sociolinguístico e buscou investigar a realização de /1/ pósvocálico na fala popular da comunidade quilombola de Alto Alegre. Destacam-se neste trabalho os fatores sociais que condicionam a variável em análise. Os dados foram coletados por meio de entrevistas junto a 12 informantes da comunidade, que é pertencente ao município baiano Presidente Tancredo Neves, localizado a $250 \mathrm{~km}$ de Salvador-BA. Os informantes foram estratificados segundo Sexo e Faixa Etária. Verificaram-se três variantes de /1/: a vocalização [w], o apagamento [Ø] e a aspiração [h]. Os resultados mostram que há um quadro de implementação de variedades da norma culta na comunidade, no sentido de que os mais jovens estão abandonando formas típicas do português popular, como, por exemplo, a aspiração, em que o falante pronuncia barde (ba[h]de) em vez de balde (ba[w]de).
\end{abstract}

Palavras-Chave: Sociolinguística; Variação de /1/ em coda silábica; Fatores sociais.

\footnotetext{
Endereço eletrônico: bem_fsa@hotmail.com.

Endereço eletrônico: jacymota@gmail.com.

Endereço eletrônico: gredsons@bol.com.br.
} 
Abstract: This sociolinguistic study investigates the realization of post-vowel /l/ in the popular speech from the quilombola community at Alto Alegre. This work highlights the social factors that condition the variable under analysis. The data were collected by interviewing with 12 speakers from the community, which belongs to the city of Presidente Tancredo Neves, located $250 \mathrm{~km}$ from Salvador-BA. The informants were stratified according to sex and age group. There were three variants of $/ \mathrm{l} /:$ vocalization $[\mathrm{w}]$, deletion $[\varnothing]$ and aspiration $[\mathrm{h}]$. The results show that there is a framework for the implementation of varieties towards the formal norm in the community, in the sense that younger people are abandoning typical forms of informal Portuguese, such as, for example, aspiration, in which the speaker pronounces barde (ba[ก]de) instead of balde (ba[w]de).

Keywords: Sociolinguistics; Linguistic variation of /l/ in syllabic coda; Social factors.

\section{INTRODUÇÃO}

A realização de /1/ pós-vocálico é variável no Português Brasileiro (PB), a exemplo das palavras alto a[w]to e capital capita[w], que também, dentre outras formas, podem ser realizadas como a[h]to e capita $\varnothing$, respectivamente. Essa variação não é aleatória; pelo contrário, é motivada pelas diferenças sociais que interferem nos usos linguísticos. Teixeira (1988) e Santos (2017) empreenderam busca para tentar explicar esse fenômeno em comunidades do território baiano. Esses autores verificaram que as trilhas desse fenômeno sugerem uma tendência à mudança em favor da variante vocalizada ${ }^{4}[\mathrm{w}]$, de modo que a forma aspirada [h] e seu apagamento [Ø] têm sido abandonados pelos membros mais jovens das comunidades analisadas.

Como observa Labov (2008 [1972], p. 194):

Os dados mais simples para se estabelecer a existência de uma mudança linguística são um conjunto de observações de duas gerações sucessivas de falantes - gerações de características sociais comparáveis que representam estágios na evolução da mesma comunidade de fala. (LABOV, 2008 [1972], p. 194)

\footnotetext{
4 Termo técnico tradicionalmente empregado em fonologia para denominar processos segmentais que afetam consoantes e têm como resultado a perda do caráter consonantal desses segmentos.
} 
Nessa perspectiva, este estudo buscou investigar a realização de /1/ pósvocálico na fala popular de falantes da comunidade quilombola de Alto Alegre, destacando os fatores sociais que influenciam o fenômeno variável. Os dados foram coletados por meio de entrevistas junto a 12 informantes de Alto Alegre, comunidade quilombola pertencente ao município baiano Presidente Tancredo Neves, localizado a $250 \mathrm{~km}$ de Salvador-BA. Seguindo a metodologia da sociolinguística variacionista (WEINREICH; LABOV; HERZOG, 2006 [1968]; LABOV, 2008 [1972]), os falantes foram estratificados segundo Sexo/Gênero (masculino e feminino), Faixa Etária (faixa I: 20-40; faixa II: 41-60; faixa III: acima de 60) e Escolarização (no máximo até a $4^{\underline{a}}$ série). Os dados revelaram três variantes de /1/ pós-vocálico: a vocalização [w], o apagamento [Ø] e a aspiração [h].

A seguir, o texto se organiza em cinco seções: a primeira, em que se apresentam os estudos dialetais pioneiros sobre a realização de /l/ em coda silábica no PB; a segunda, em que são destacados três estudos que, numa perspectiva sociolinguística, abordaram o fenômeno; a terceira, em que aspectos teóricos sobre os fatores sociais e a variação linguística são considerados a partir da ótica de Weireinch, Labov, Herzog (2006 [1968]) e Labov (2008 [1972]). Na quarta e na quinta seções, apresentam-se a metodologia e a discussão dos resultados encontrados, ao que se seguem as considerações finais.

\section{O /1/ PÓS-VOCÁLICO NO PB: PRECURSORES}

A variação do /1/ pós-vocálico no PB foi registrada ainda na primeira metade do século XX por três importantes estudos de autores brasileiros: $O$ dialeto caipira de Amaral (1955 [1920]), O linguajar carioca de Nascentes (1953 [1922]) e A Língua do Nordeste: Alagoas e Pernambuco de Marroquim (2008 [1934]), que 
compõem a tríade de estudos monográficos da dialetologia brasileira daquela época.

Em O dialeto caipira, é registrada a diferenciação dialetal do falar brasileiro:

O falar do Norte do país não é o mesmo que o do Centro ou o do Sul. O de S. Paulo não é igual ao de Minas. No próprio interior deste Estado se podem distinguir sem grande esforço zonas de diferente matiz dialetal - o Litoral, o chamado 'Norte', o Sul, a parte confinante com o Triângulo Mineiro. (AMARAL, 1955 [1920], p. 43)

No que tange à variação do /1/ em final de sílaba, Amaral (1955 [1920], p. 52) assinala que essa consoante passa a $r$, como em quarquér, papér, mér e arma por qualquer, papel, mel e alma. Verificou também que em locuções como tal qual e mal, mal (mal e mal ou mal a mal) o último $l$ é apagado, e o primeiro se torna intervocálico, talequá e malemá. As palavras terminadas em al, el e il sofrem apócope da consoante final; mas, antes do apagamento desse fonema, primeiro o $l$ tornou-se $r$ : mal, sol, jornal > már, sór, jornár > má, só, jorná; assim, há uma ordenação de regras: $1>$ r > Ø. Nos termos de Amaral (1955 [1920], p. 52), esse fenômeno era mais frequente entre os negros, os quais, quando no mesmo meio, se diferiam linguisticamente dos brancos e dos caboclos.

Outro estudo sobre a variação do /1/ pós-vocálico no PB é o de Nascentes (1953 [1922]), o qual considera que o linguajar carioca é uma variedade do subfalar fluminense e buscou caracterizar essa variedade do português do Brasil a partir da abordagem de tópicos da estrutura linguística como a fonética, a morfologia, a sintaxe e o léxico. Nesse sentido, a respeito da consoante /1/ em coda silábica no campo da variação fonética, Nascentes diz que "o $l$ final é pronunciado levemente pela classe culta; os pedantes exageram-no. A classe semiculta vocaliza-o diante de $a, e, i$, num $u$ vogal que tem de comum com ele a qualidade de velar" (NASCENTES, 1953 [1922], p. 48), a exemplo de qual/quau/quá, papel/papeu/papé, Brasil/Brasiu/Brasi. 
Ao tratar de sequência de duas consoantes, na mesma sílaba ou em sílabas subsequentes, no item intitulado Consoantes ligadas, o dialetólogo menciona que o $l$ seguido de consoante:

na classe inculta passa para $r$, pelo mesmo motivo acima apontado nas consoantes seguidas de l: Albino-arbino, calcar-carcá, maldito-mardito, alfandega-arfandega, algum-argum, alma-arma, golpe-gorpe, falso-farso, falta-farta, alvo-arvo, colcha-corcha, colza-corza". (NASCENTES, 1953 [1922], p. 55)

Nesses argumentos, verifica-se que o autor relaciona a variação da consoante com fatores externos à língua, a classe do falante, marcando três categorias: culta, semiculta e inculta, nos termos de Nascentes (1953 [1922], p. 53), de modo que o desprestígio se acentua sobre a variante desta última classe.

O terceiro estudo da tríade sobre o /1/ em coda é a Língua do Nordeste: Alagoas e Pernambuco, de Mário Marroquim. Dentre os aspectos da língua abordados na obra, tratou, em especial, a respeito da fonologia do falar do Nordeste. No tocante à variação do /1/ em final de sílaba, Marroquim (2008 [1934]) verificou, na variedade brasileira do português, a troca do $r$ pelo $l$ na linguagem popular, como em carçada, sordado e arvura por calçada, soldado e alvura.

Considerando que as consoantes finais caem ou são vocalizadas na língua do povo, a exceção do $s$ indicador de plural no artigo, nos numerais e demonstrativos, Marroquim (2008 [1934], p. 63) sugere que depois da passagem do $l$ a $r$, processase a vocalização do último, de modo que o $r$ aparece em substituição ao $l$, e o $i$ resultante da vocalização do $r$, a exemplo de arvura, aivura, de alvura, o que também indica uma ordenação de regras $1>r>i$.

\section{ESTUDOS DO /l/ EM CODA NO PB EM PERSPECTIVA SOCIOLINGUÍSTICA}

Os dados da comunidade de Saco Fundo, povoado de Monte Santo na Bahia, foram tratados em Teixeira (1988) que encontrou as seguintes variantes de 
/1/ em posição pós-vocálica interna (ex.: balde) e externa (capital) à palavra: velarizada $[\mathrm{H}]$, vocalizada $[\mathrm{w}]$, aspirada $[\mathrm{h}]$, alveolar $\left[\mathrm{l}^{\mathrm{i}}\right]$, bem como seu apagamento [Ø]. Quanto à distribuição dessas variantes nas posições interna e externa de palavras, Teixeira (1988) constatou que a aspiração [h] da consoante somente ocorre em posição interna e a realização alveolar $\left[1^{\mathrm{i}}\right]$, que recebe uma vogal de apoio como em mali por mal, em posição externa. Assim, das cinco variantes, há quatro variantes em posição interna e quatro variantes em posição externa, visto que as ocorrências das variantes $\left[\mathrm{l}^{\mathrm{i}}\right]$ e $[\mathrm{h}]$ ficaram restritas, respectivamente, às posições externa e interna de palavra.

Teixeira (1988) verificou que a variante vocalizada [w] está substituindo as variantes [ $[\mathrm{e}]$ e $\left[\mathrm{l}^{\mathrm{i}}\right]$ na fala dos habitantes da comunidade, e que o apagamento [Ø] surge como uma extensão da vocalização [w], sugerindo o seguinte direcionamento de mudança: $[\mathrm{t}]>[\mathrm{w}]>[\varnothing]$.

Tasca (2002) destaca o fato de a alofonia de /1/ não se restringir ao português europeu (PE) nem ao $\mathrm{PB}$, visto que é um fenômeno já verificado no próprio latim e em línguas modernas, como, por exemplo, no francês e no inglês.

Com dados de João Pessoa-PB, Hora (2006) verificou que a ocorrência da aspiração [h] de /l/ ocorreu apenas em interior de vocábulo e a ocorrência da variante $[\varnothing]$, principalmente, em final de vocábulo, podendo ocorrer com menor frequência em interior de palavra. Essa análise mostrou que a Faixa Etária é relevante enquanto fator que influencia a realização de /1/; em tempo aparente, com pesos relativos de 0,55 e 0,58, os falantes mais jovens (entre 15 e 25 anos) e os da faixa etária intermediária (entre 26 e 49 anos), respectivamente, favorecem a ocorrência da variante vocalizada, já aqueles acima de 49 anos, com peso relativo de 0,37 , desfavorecem esse último tipo de ocorrência.

Segundo Sá (2006, p. 7), ao confrontar as ocorrências de /1/ no PB e no espanhol, a partir da comparação de diferentes estudos nessas línguas, "[...] a forma vocalizada $[\mathrm{w}]$ parece constituir a tendência geral no dialeto brasileiro", 
visto que a vocalização é apontada como fenômeno mais inovador na evolução do /1/ em posição de coda silábica. O autor registra ainda que, nas regiões que não constituem grandes centros urbanos, verificam-se variantes glotais e apagamento [Ø].

Outro estudo que analisou o fenômeno em questão foi o de Leite, Callou e Moraes (2007). Com base nos dados recolhidos pelo projeto NURC nas cidades brasileiras de Porto Alegre, São Paulo, Rio de Janeiro, Salvador e Recife, os autores observaram, como principal resultado, que a variante vocalizada se encontra em estágio avançado entre a população mais jovem.

Santos (2017), ao investigar a realização variável da lateral pós-vocálica /1/ em seis localidades baianas do Projeto Atlas Linguístico do Brasil (ALiB), verificou que a variante $[w]$ se encontra amplamente difundida entre os membros das comunidades, de modo que os indivíduos mais jovens lideram sua implementação, abandonando as formas utilizadas pelos mais velhos ([h] e $[\varnothing])$, sugerindo, assim, uma tendência à mudança. Nesse estudo, a vocalização também foi favorecida pelos indivíduos do sexo feminino.

\section{FATORES SOCIAIS DA VARIAÇÃO}

Weinreich, Labov e Herzog (2006 [1968]) consideram que fatores extralinguísticos e/ou linguísticos interferem no processo de mudança e o papel da teoria é determinar o conjunto de condições possíveis para uma mudança linguística. Isso se aplica aos casos em que duas ou mais variantes, por exemplo, se encontram em situação de competição no sistema, de modo que a substituição de uma pela outra no mesmo contexto não implique mudança de significado, e sob certas condições especiais a direção da mudança será em favor de uma das variantes. 
A variação linguística é justamente a possibilidade de uso de duas formas linguísticas diferentes para se dizer uma mesma coisa, com o mesmo significado, em um dado contexto. Essa possibilidade da língua revela seu aspecto heterogêneo, de modo que a variação passa a ser entendida como mecanismo inerente ao próprio sistema linguístico, atuando também como propulsora da mudança linguística.

O fato de a variação ser propulsora da mudança linguística não significa necessariamente que toda variação leva à mudança. O que se diz é que toda mudança é precedida de variação (WEINREICH; LABOV; HERZOG, 2006 [1968]).

Longe de ser homogênea e imutável, a língua é heterogênea e variável precisamente para atender o seu objetivo enquanto "instrumento de comunicação usado pela comunidade de fala" (LABOV, 2008 [1972], p. 220). Contudo, essa heterogeneidade não acontece de maneira aleatória, como se estivesse à deriva (WEINREICH; LABOV; HERZOG, 2006 [1968], p. 125); pelo contrário, é dotada de regra variável perfeitamente passível de sistematização e análise, ou seja, trata-se de uma heterogeneidade ordenada.

Para Labov (2008 [1972]), nenhuma mudança acontece num vácuo social. É perfeitamente possível reconstruir a história da mudança e identificá-la enquanto ocorre no momento presente, isolando os fatores linguísticos e os fatores sociais a partir da correlação dos padrões linguísticos com diferenças concomitantes na estrutura social. Nesse sentido, ao extrair os fatores sociais que incidem sobre o processo linguístico, os resultados desse procedimento poderão contribuir para a compreensão geral do processo de mudança linguística. Os fatores Sexo/Gênero e Idade/Faixa Etária dos indivíduos, por exemplo, são fatores externos à estrutura linguística que, no entanto, evidenciam fortes relações com os usos da língua, constituindo-se em fatores indissociáveis da interação linguística. 
Essas diferenças sociais estão diretamente relacionadas com as diferenças na estrutura linguística. Nesse sentido, Santos (2017, p. 14) diz que:

A partir das contribuições dos estudos sociolinguísticos iniciados na década de 1960, assume-se que a variação é inerente às línguas, contudo tal entendimento somente pode ser concebido a partir de uma abordagem linguística que leve em consideração o fato de que a língua e a sociedade não se encontram dissociadas, de que sem sociedade não haverá língua e, reciprocamente, sem língua não haverá sociedade. (SANTOS, 2017, p. 14)

A explicação da variação e da mudança linguísticas não pode prescindir da correlação entre fatores linguísticos e sociais - a covariação -, uma vez que língua e sociedade não estão dissociadas. Ainda que a apresentação de resultados se dê separadamente a partir de fatores internos ou externos, o processamento e análise dos dados não podem fugir da responsabilidade de estabelecer essa correlação. No presente estudo, são apresentados os fatores sociais relacionados à variação de /1/ em posição de coda silábica. A apresentação dos resultados parte justamente da correlação feita entre fatores sociais e fatores linguísticos. $\mathrm{O}$ destaque dos fatores sociais se explica pelo interesse em ressaltar os indícios de mudança que foram detectados.

Uma possibilidade de se averiguar a variação e mudança linguística é por meio do que Labov (1994, apud FREITAG, 2005) chamou de tempo aparente:

[...] estratégia para identificar, descrever e analisar um dado fenômeno de variação ou de mudança lingüística em um período de tempo reduzido proposta por Labov (1994) é que a mudança pode ser observada em tempo aparente. Ou seja, analisar o comportamento do fenômeno em função das faixas etárias. (FREITAG, 2005, p. 110)

Esse recurso metodológico consiste em relacionar diferentes idades com o objetivo de acessar cronologicamente certos momentos do passado e do presente dos usos linguísticos por meio das faixas etárias, analisando o fenômeno num dado espaço de tempo. Isso pode favorecer o conhecimento da variação e da 
mudança de maneira rápida, uma vez que não é preciso esperar anos para comparar dados coletados em momentos distantes no tempo, por meio da aplicação do recurso metodológico de estudo em tempo real.

Contudo, a análise com base no tempo aparente não pode assumir a mudança linguística como conclusiva, uma vez que se está tratando do tempo hipotético, um simulacro. Para tal, é necessária a conjugação dos dois recursos metodológicos.

\section{METODOLOGIA}

Para investigar a variação de /l/ pós-vocálico no português falado na comunidade quilombola de Alto Alegre, foram analisadas 444 ocorrências marcadas pela presença do fenômeno variável, com 12 informantes.

O corpus analisado pertence ao Projeto de pesquisa $A$ coda silábica no português da comunidade quilombola de Alto Alegre: análise sociolinguística que buscou investigar se a intensidade da variação das consoantes /S/, /L/, /R/ pósvocálicas no português da comunidade pode ser associada à história de contato entre o português e as línguas africanas faladas pelos escravos que fundaram a comunidade. Esse projeto, vinculado ao CNPq, foi coordenado pelo professor Dr. Gredson dos Santos, da Universidade Federal do Recôncavo da Bahia (UFRB), no período de 2013 a $2014^{5}$. As primeiras análises de /1/ pós-vocálico a partir desses dados estão em Santos (2015).

Neste trabalho, são consideradas como variantes do fenômeno a aspiração [h], que diz respeito às realizações não padrão da consoante /l/ em posição pósvocálica, como, por exemplo, ba[h]de em vez de balde, com grau social de estigmatização alto; a vocalização $[\mathrm{w}]$, que é uma realização mais aceita

\footnotetext{
5 No período de execução do projeto, não havia ainda um Conselho de Ética constituído na universidade. Tampouco era praxe na instituição submeter os projetos a um conselho de ética.
} 
socialmente, como, por exemplo, na pronúncia $a[\mathrm{w}]$ to da palavra alto; e o apagamento [Ø], que diz respeito à ausência do fonema na realização da palavra, como, por exemplo, pessoaØ em vez de pessoal.

A coleta de dados foi pautada na metodologia de recolha e análise da sociolinguística variacionista (WEINREICH; LABOV; HERZOG, 2006 [1968]); LABOV, 2008 [1972]). Assim, os 12 informantes foram estratificados igualitariamente segundo Sexo/Gênero (masculino e feminino), Faixa Etária (faixa I: 20-40; faixa II: 41-60; faixa III: acima de 60) e todos com Escolarização de no máximo até a $4^{\underline{a}}$ série.

Para uma visão geral do trabalho, apesar de não serem tratados aqui, os grupos de fatores internos submetidos à análise foram: Posição da Variável na Palavra, Tonicidade da Sílaba, Extensão do Vocábulo, Vogal Precedente e Classe Morfológica. Desses grupos, foram selecionados pelo programa computacional como relevantes para a aspiração [h] o de Classe Morfológica e o de Vogal Precedente, e para o apagamento $[\varnothing]$ os cinco grupos foram selecionados.

Os dados foram codificados e analisados pelo programa Goldvarb $\mathrm{X}$ (SANKOFF; TAGLIAMONTE; SMITH, 2005). Trata-se de um programa que, a partir de uma análise estatística multivariada, processa os dados operando com grupos de fatores e com resultados em pesos relativos e significância. Nesta investigação, são apresentados, a seguir, os resultados do grupo de fatores extralinguísticos (Faixa Etária) selecionado pelo programa computacional a partir de duas rodadas binárias ([h] versus $[\mathrm{w}]$ e [Ø] versus $[\mathrm{w}])$, tendo como valor de aplicação as variantes consideradas socialmente estigmatizadas: [h] e [Ø].

\section{APRESENTAÇÃO E DISCUSSÃO DOS RESULTADOS}

A Tabela 1 apresenta a distribuição geral dos dados. 
Tabela 1: Distribuição geral dos dados

\begin{tabular}{ccccc}
\hline & {$[\mathrm{h}]$} & {$[\varnothing]$} & {$[\mathrm{w}]$} & Total \\
\hline № & 91 & 116 & 237 & 444 \\
$\%$ & 21 & 26 & 53 & 100 \\
\hline
\end{tabular}

Foram registradas três variantes na fala da comunidade: vocalização [w], aspiração [h] e apagamento [Ø]. De um total de 444 ocorrências, $21 \%$ foram da variante aspirada [h], com 91 dados; 26\% de apagamento [Ø], com 116 dados, e 53\% de vocalização [w], com 237 dados. Desses percentuais, destaca-se o valor apresentado pela variante aspirada [h], com $21 \%$, índice bastante alto em relação aos apresentados em outros estudos, como em Santos (2017), em que essa variante atingiu o percentual de $2 \%$ dos dados no conjunto das comunidades analisadas. Sá (2006) apontou que essa é uma variante estigmatizada e que marca presença nas regiões que não constituem grandes centros urbanos.

A questão é se a realização aspirada [h] pode ser atribuída ao falar de pessoas de procedência rural. Estudos de cunho sociolinguísticos podem responder a partir do confronto de resultados de análises do fenômeno em diferentes comunidades urbana e rural.

Some-se a essas observações o fato de que Alto Alegre, sendo quilombola e situada em zona rural, é uma comunidade falante do tipo das que Lucchesi, Baxter e Ribeiro (2009) designaram de português afro-brasileiro, variedade que possui especificidades em relação às demais normas populares do PB. Do ponto de vista fonético, como evidenciou Santos em dois artigos $(2012,2020)$, o português afro-brasileiro, no que tange às consoantes em coda silábica, apresenta altas taxas das variantes estigmatizadas mesmo quando se consideram outras variedades do português popular.

Amaral (1955 [1920], p. 52) mencionou que, antes de seu apagamento, primeiro o $l$ tornou-se $r$ : mal, sol, jornal > már, sór, jornár > má, só, jorná, sendo esse 
fenômeno mais frequente entre os negros, os quais, quando no mesmo meio, se diferiam linguisticamente dos brancos e dos caboclos, nos termos desse autor. Vêse que o estigma sobre as variantes [h] e [Ø] não é recente; Nascentes (1953 [1922]) atribui a transformação de /l/ pós-vocálico em consoante aspirada [h] à classe inculta.

Santos (2017), ao analisar seis localidades que compõem a rede de pontos do Projeto $\mathrm{ALiB}$, verificou que o maior índice de ocorrência de aspiração de /1/ pós-vocálico foi de apenas 6\% no município baiano de Seabra. As demais cidades apresentaram percentuais da variante aspirada [h] entre 1\% e 3\% (SANTOS, 2017, p. 80). Destaque-se também, na Tabela 1, o valor de 53\% apresentado pela variante vocalizada [w], visto que nas seis localidades do ALiB os índices ficaram entre $74 \%$ e $90 \%$. Quanto à variante apagamento [Ø], com 26\%, também apresentou índice um pouco acima daqueles encontrados por Santos (2017), que foram entre $9 \%$ e 20\%. Essa comparação sugere que a variação de /1/ pós-vocálico pode estar diretamente associada ao contexto sócio-histórico de formação da comunidade, considerando que a intensidade do contato linguístico resultou na diversidade linguística do PB, marcando variedades segundo a história de cada comunidade.

Questão importante a ser investigada com maior sistematicidade é se esse quadro de variação de /1/ pós-vocálico em Alto Alegre seria um aspecto comum às comunidades rurais ou se seria um aspecto específico de comunidades quilombolas, como até então as análises empreendidas por Santos $(2012,2020)$ e Santos e Almeida $(2016,2017)$ sugerem. O estudo de outras comunidades reconhecidamente quilombolas e de outras apenas rurais no território baiano poderão trazer luz a esse questionamento, bem como a extensão deste estudo a outras localidades desse território. 


\subsection{Aspiração [h] de /1/ pós-vocálico: fatores sociais}

Os fatores extralinguísticos considerados no tratamento dos dados foram o Sexo/Gênero e a Faixa Etária dos informantes; no entanto, somente o último foi selecionado pelo programa Goldvarb X como estatisticamente relevante na rodada binária entre a variante aspirada [h] como valor de aplicação e a variante vocalizada $[\mathrm{w}]$.

A Tabela 2 apresenta a distribuição dos dados segundo a Faixa Etária dos informantes. Como foi dito na Seção 4, na constituição da amostra, foram estabelecidos informantes com escolaridade até a quarta série, especialmente porque, na comunidade, os falantes da faixa etária 3 eram todos sem escolarização - fator social que marca as comunidades de falantes do português afro-brasileiro. Em outras palavras, houve knockout nessa variável e, em razão disso, os dados não puderam ser analisados no grupo de fatores escolaridade.

Tabela 2: Distribuição dos dados de aspiração [h] e vocalização [w] por Faixa Etária

\begin{tabular}{cccc}
\hline Faixa etária & {$[\mathrm{h}]$} & {$[\mathrm{w}]$} & Total \\
\hline I (20 a 40) & & & \\
№ & 12 & 120 & 132 \\
$\%$ & 9 & 91 & 40 \\
II (41 a 60) & & & \\
№ & 11 & 84 & 95 \\
$\%$ & 12 & 88 & 29 \\
III (acima de 60) & & & \\
№ & 68 & 33 & 101 \\
$\%$ & 67 & 33 & 31 \\
Total & & & \\
№ & 91 & 237 & 328 \\
$\%$ & 28 & 72 & 100 \\
\hline
\end{tabular}

Verifica-se na Tabela 2 que a aspiração da lateral é pouco produtiva na fala dos informantes das faixas etárias mais jovem e intermediária, com 9\% e 12\%, respectivamente, predominando o uso da vocalização entre esses sujeitos, com taxas de $91 \%$ e $88 \%$ de aplicação para as faixas mais jovens e intermediária, 
respectivamente. Diferentemente, entre os informantes acima de 60 anos, a aspiração predomina, com 67\%, enquanto a vocalização registrou apenas 33\% nessa faixa. Dos 328 dados dessas duas variantes, a aspiração representa 28\%, com 91 ocorrências; a vocalização, 72\%, com 237 ocorrências.

A Tabela 3 apresenta os pesos relativos dos fatores que influenciam o fenômeno variável. O input inicial da rodada foi de 0,277 e o final foi de 0,149 . O log likelihood ${ }^{6}$ foi de $-93,399$ e o nível de significância7 foi de 0,000. De posse desses números, verifica-se que se trata de uma rodada cujos resultados são confiáveis.

A Faixa Etária dos informantes foi o primeiro grupo selecionado na ordem de importância atribuída pelo Goldvarb X, seguido da Classe Morfológica do Vocábulo e da Vogal Precedentes, nessa ordem. A Tabela 3 mostra a influência da Faixa Etária dos informantes no comportamento da variante aspirada.

Tabela 3: Aspiração [h] x vocalização [w]

\begin{tabular}{crrr}
\hline Faixa etária & Oc./Total & $\%$ & PR $^{*}$ \\
\hline I (20 a 40) & $12 / 132$ & 9 & 0,18 \\
II (41 a 60) & $11 / 95$ & 12 & 0,27 \\
III (acima de 60) & $68 / 101$ & 67 & 0,94 \\
\hline *PR = Peso Relativo & &
\end{tabular}

Como apresentado na Tabela 3, os valores dos pesos relativos mostram que os indivíduos acima de 60 anos favorecem a aspiração de /1/ pós-vocálico,

\footnotetext{
6 Conforme Guy e Zilles (2007), trata-se de um logaritmo de verossimilhança que mede a qualidade da aproximação entre o modelo apresentado pelos pesos relativos e os dados observados, quanto mais próximo a zero o log likelihood, maior será a robustez dos dados.

7 “Uma das formas de apresentação dos valores de significância é por meio da convencionada 'hipótese nula', representada por ' $p$ '. A hipótese nula indica sempre que não há uma relação entre as 'variáveis independentes' (fatores que influenciam o fenômeno estudado) e a 'variável dependente' (fenômeno estudado) e que os dados se encontram numa distribuição aleatória. Isso significa dizer que, quanto mais baixa a probabilidade da hipótese nula $\mathrm{p}=0,05$ ou $\mathrm{p}=0,01$, os efeitos e a relação entre as variáveis independentes e a variável dependente são verdadeiros, ou seja, são significantes na distribuição observada" (GUY; ZILLES, 2007, apud SANTOS, 2017, p. 70).

8 O tratamento dos fatores internos apontados será feito em trabalhos futuros.
} 
com peso relativo de 0,94 , enquanto a faixa etária intermediária e a mais jovem a desfavorecem, com pesos relativos de 0,27 e de 0,18, respectivamente. Esse quadro sugere haver o abandono da variante aspirada pelos mais jovens em favor da implementação da vocalização na comunidade de Alto Alegre, podendo entrever uma tendência à mudança que já alcança a faixa etária intermediária até 60 anos.

\subsection{Apagamento [Ø] de /1/ pós-vocálico: fatores sociais}

No confronto entre o apagamento e a vocalização da consoante lateral, tendo a variante $[\varnothing]$ como valor de aplicação, o programa estatístico também selecionou a Faixa Etária dos informantes como único grupo de fatores extralinguísticos e como o mais relevante em ordem de importância em relação aos fatores linguísticos selecionados. A distribuição dos dados dessas variantes por Faixa Etária é apresentada na Tabela 4.

Tabela 4: Distribuição dos dados de apagamento [Ø] e vocalização por Faixa Etária

\begin{tabular}{cccc}
\hline Faixa etária & [Ø] & [w] & Total \\
\hline I (20 a 40) & & & \\
№ & 16 & 120 & 136 \\
$\%$ & 12 & 88 & 38 \\
II (41 a 60) & & & \\
№ & 52 & 84 & 136 \\
$\%$ & 38 & 62 & 39 \\
III (acima de 60) & & & \\
№ & 48 & 33 & 81 \\
$\%$ & 59 & 41 & 23 \\
Total & & & \\
No & 116 & 237 & 353 \\
\% & 33 & 67 & 100 \\
\hline
\end{tabular}

A variante de preferência dos indivíduos mais velhos é o apagamento, com taxa de 59\%, decrescendo entre os da faixa etária intermediária, com taxa de $38 \%$, e entre a faixa mais jovem, com taxa de $12 \%$. Entre os sujeitos desta última 
faixa, a vocalização apresenta taxa de $88 \%$ de ocorrência, $62 \%$ entre os de faixa etária intermediária e 41\% entre aqueles acima de 60 anos.

A Tabela 5 apresenta os pesos relativos dos fatores que influenciam o fenômeno variável. O input inicial da rodada foi de 0,329 e o final foi de 0,196. O log likelihood foi de -145,438 e o nível de significância foi de 0,001.

Tabela 5: Apagamento x vocalização

\begin{tabular}{crrc}
\hline Faixa etária & Oc./Total & $\%$ & $\mathrm{PR}^{*}$ \\
\hline I (20 a 40) & $12 / 132$ & 9 & 0,17 \\
II (41 a 60) & $11 / 95$ & 12 & 0,61 \\
III (acima de 60) & $68 / 101$ & 67 & 0,86 \\
\hline *PR = Peso Relativo & &
\end{tabular}

A Tabela 5 mostra que a variante apagamento é favorecida principalmente pelos membros mais velhos da comunidade, com peso relativo de 0,86 , sendo acompanhados pelos sujeitos da faixa etária intermediária, com peso relativo de 0,61, e desfavorecida por aqueles que compõem a faixa etária mais jovem, com peso relativo de 0,17 .

Com base na configuração desse quadro variável, pode-se apontar uma tendência à mudança, em que os informantes mais jovens começam a abandonar formas típicas da comunidade, [Ø], em favor da implementação da variante vocalizada $[\mathrm{w}]$. Esse sugestivo estágio de mudança ainda parece encontrar resistência entre as pessoas da faixa etária intermediária, que apresentam preferência pelo apagamento da consoante lateral em final de sílaba. Tal configuração dos dados reforça, pois, os principais aspectos que marcam as comunidades falantes do português afro-brasileiro, conforme Lucchesi, Baxter e Ribeiro (2009) e Santos (2020). 


\section{CONCLUSÕES}

Este estudo buscou investigar a realização de /1/ pós-vocálico na fala popular de falantes da comunidade de Alto Alegre, destacando os fatores sociais que condicionam o fenômeno variável, pautando-se no modelo teórico da Sociolinguística variacionista (WEINREICH; LABOV; HERZOG, 2006 [1968]; LABOV, 2008 [1972]).

Verificou-se que o grupo de fator Faixa Etária foi o único extralinguístico selecionado pelo programa Goldvarb X e considerado em primeiro lugar na ordem de importância atribuída aos grupos que influenciam a realização de /1/ pós-vocálico, sendo que os demais foram grupos de fatores linguísticos ou internos, como já referido na seção de metodologia.

Em comparação aos resultados apresentados em Santos (2017), as taxas de ocorrências das variantes estigmatizadas socialmente, [h] e [Ø], encontradas em Alto Alegre diferenciam significativamente o quadro variável do fenômeno analisado nessa comunidade em relação a outras localidades baianas, uma vez que são, especificamente, urbanas.

A análise da rodada binária entre a aspiração e a vocalização sugere haver o abandono da variante estigmatizada socialmente [h] pelos mais jovens em favor da implementação da vocalização na comunidade de Alto Alegre, podendo entrever uma tendência à mudança que já alcança a faixa etária intermediária até 60 anos.

Com relação ao apagamento $[\varnothing]$, aponta-se uma tendência à mudança, em que os informantes mais jovens começam a abandonar formas típicas da comunidade, [Ø], em favor da implementação da variante vocalizada [w]. Esse sugestivo estágio de mudança ainda parece encontrar resistência entre as pessoas da faixa etária intermediária que apresentam preferência pelo apagamento da consoante lateral em final de sílaba. Os índices percentuais e os pesos relativos 
mostram que a vocalização se encontra amplamente difundida entre os membros da comunidade de Alto Alegre de faixa etária mais jovem.

\section{REFERENNCIAS}

AMARAL, Amadeu. O dialeto caipira. São Paulo: Anhembi, 1955 [1920].

FREITAG, Raquel Meister Ko. Idade: uma variável sociolinguística complexa. Línguas $\mathcal{E}$ Letras. Cascavel, v. 6, n. 2, p. 105-121, 2오 sem. 2005.

GUY, Gregory R.; ZILLES, Ana Maria. Sociolinguística quantitativa - instrumental de análise. São Paulo: Parábola, 2007.

HORA, Dermeval da. Variação da lateral /1/: correlação entre restrições sociais e estruturais. Scripta, Belo Horizonte, v. 9, n. 18, p. 29-44, 1ํㅗㅇ semestre 2006.

LABOV, William. Padrões sociolinguísticos. Tradução de Marcos Bagno. São Paulo: Parábola, 2008 [1972].

LABOV, William. Principles of Linguistic Change: Internal Factors. Oxford: Blackwell, 1994.

LEITE, Yonne; CALLOU, Dinah; MORAES, João. O /1/ em posição de coda silábica: confrontando variedades. 22 ENCONTRO NACIONAL DA ASSOCIAÇÃO PORTUGUESA DE LINGUÍSTICA, 2007, 22. Lisboa. Atas... Lisboa: APL, 2007. p. 423430.

LUCCHESI, Dante; BAXTER, Alan; RIBEIRO, Ilza (Orgs.). O português afro-brasileiro. Salvador: EDUFBA, 2009.

MARROQUIM, Mário. A língua do Nordeste: Alagoas e Pernambuco. 4. ed. Maceió: EDUFAL, 2008 [1934].

NASCENTES, Antenor. O linguajar carioca. Rio de Janeiro: Organização Simões, 1953 [1922].

SÁ, Edmilson José de. O uso variável da lateral /1/ posvocálica em posição de coda em português e espanhol. Revista Virtual de Estudos da Linguagem - ReVEL, ano 4, n. 7, ago. 2006.

SANKOFF, David; TAGLIAMONTE, Sali. A.; SMITH, Ellen. Goldvarb X - a multivariate analysis application. Toronto: Department of Linguistics; Ottawa: Department of Mathematics, 2005.2 Disponível em: <http://www.tarkvara.org/goldvarb/GoldVarb30b3.zip> Acesso em 27 fev. 2020.

SANTOS, Gredson dos. Afro-brazilian portuguese: revisiting the concept based on a sociolinguistic analysis of quilombola communities in Bahia, Brazil. In: JUNGBLUTH, Konstanze; VALLENTIN, Rita; SAVEDRA, Mônica (Orgs.) Language. Belonging. Politics: Impacts for a Future of Complex Diversities. Nomos Verlagsgesellschaft, Baden-Baden, 2020 (no prelo). 
SANTOS, Gredson dos. O português afro-brasileiro de Helvécia-Ba: análise da variável $<\mathrm{s}>$ em coda silábica. 274 f. il. 2012. Tese (Doutorado em Letras e Linguística) - Instituto de Letras, Universidade Federal da Bahia, Salvador, 2012.

SANTOS, Gredson; ALMEIDA, Jailma da Guarda. Aspiração e apagamento de S em coda silábica no português quilombola de Alto Alegre-BA. Papia, São Paulo, v. 26, n. 1, p. 101-112, jan./jun. 2016.

SANTOS, Gredson; ALMEIDA, Jailma da Guarda. O ditongo decrescente no português falado pela comunidade quilombola de Alto Alegre. Letrônica: Revista Digital do Programa de Pós-Graduação em Letras da PUCRS, Porto Alegre, v. 10, n. 1, p. 239-252, janeiro-junho 2017.

SANTOS, Robevaldo Correia. A variação da lateral pós-vocálica /l/ no português quilombola de Alto Alegre: análise sociolinguística. 2015. 70 f. Trabalho de Conclusão de Curso (Graduação) - Centro de Formação de Professores, Universidade Federal do Recôncavo da Bahia, Amargosa, 2015.

SANTOS, Robevaldo Correia. A realização variável da lateral pós-vocálica /l/ em comunidades baianas do Projeto Atlas Linguístico do Brasil (ALiB). 2017. 109 f. Dissertação (Mestrado) Programa de Pós-Graduação em Estudos Linguísticos, Universidade Estadual de Feira de Santana, 2017.

TASCA, Maria. Variação e mudança do segmento lateral na coda silábica. In: BISOL, Leda; BRESCANCINI, Cláudia (Org.). Fonologia e variação: recortes do português brasileiro. Porto Alegre: EDIPUCRS, 2002. p. 268-302.

TEIXEIRA, Eliana Sandra Pitombo. Variação e mudança linguísticas na região de Monte Santo. 1988. 120 f. Dissertação (Mestrado), Instituto de Letras, Universidade Federal da Bahia, Salvador, 1988.

WEINREICH, Uriel; LABOV, Weinreich; HERZOG, Marvin. Fundamentos empíricos para uma teoria da mudança linguística. São Paulo: Parábola, 2006 [1968].

Nota do editor:

Artigo submetido para avaliação em: 05 de setembro de 2020.

Aprovado em sistema duplo cego em: 10 de fevereiro de 2021. 